\title{
UM OCEANO DE DESCONHECIMENTO SOBRE A BIODIVERSIDADE
}

$M^{a}$ Isabel Landim

DOI: https://doi.org//0265 I2/museologia.v7il4.18388

\section{RESUMO}

O Museu de Zoologia da Universidade de São Paulo abriga uma coleção centenária, com cerca de II milhões de exemplares, sendo uma das maiores do mundo com foco na biodiversidade Neotropical. Essa coleção cresceu muito em resposta às pressões antrópicas sobre a biodiversidade e a urgência na geração de conhecimento e obtenção de amostras de espécies e ambientes ameaçados. Estima-se que conhecemos entre $1-10 \%$ da biodiversidade e que o conhecimento sobre a diversidade oceânica seja ainda menor. $\mathrm{O}$ acesso aos locais de coleta e recursos necessários para realizá-las é parte da resposta. Buscamos aqui retratar como a diversidade oceânica está representada em nossas atividades de pesquisa e de extroversão. Como instituição guardiã de coleção biológica ressaltamos alguns dos desafios enfrentados também na preservação da biodiversidade ex-situ, fonte de conhecimento fundamental para a compreensão do padrões atuais e passados da diversidade biológica em nosso planeta.

\section{PALAVRAS-CHAVE}

biodiversidade; museus e coleções de história natural; pesquisa sobre acervos; conservação; oceanos.

\begin{abstract}
The University of São Paulo Museum of Zoology houses a centennial collection, with about II million specimens being one of the largest in the world focused on Neotropical biodiversity. The collection has grown in response to pressures on the biodiversity and the urgency of generating knowledge and obtaining samples of threatened environments and species. The present knowledge of the planet biodiversity is estimated as something between $\mathrm{I}-10 \%$ of the existing species and for the ocean diversity it can be even smaller. The access to the collection sites and resources needed to accomplish it is part of the answer. Here we aim to show how ocean diversity is represented in our research and outreach activities. As an organization that lives around biological collection we highlight some of the challenges faced in the preservation of ex-situ biodiversity as a main source of knowledge for understanding the past and current patterns of biodiversity on our planet.
\end{abstract}

\section{KEY WORDS}

biodiversity; museums and collections of natural history; research on collections; conservation; oceans. 
A pesquisa sobre a biodiversidade sofre uma pressão sem precedentes para a produção de resultados na forma de mais espécies descritas, maior compartilhamento de dados e velocidade na cadeia de produção do conhecimento em geral. Políticas públicas voltadas para este fim acabam priorizando investimentos que buscam resultados imediatos, às vezes os de maior impacto midiático, em detrimento das etapas iniciais do processo que garantem melhor qualidade dos resultados (Carvalho et al. 2007). Paradoxalmente, a etapa mais tradicional da pesquisa em sistemática e taxonomia, representada pelo estudo de coleções, vem sofrendo em parte do mundo forte desprestígio diante de abordagens mais tecnológicas que diga-se são complementares. Isto resulta na diminuição de financiamento de projetos de pesquisa e de pessoal em instituições que abrigam coleções biológicas (Funk, 20l4) incrementando os riscos relativos à integridade e manutenção dos acervos com valor incomensurável para a humanidade. Esta ameaça representa uma faceta da "crise da biodiversidade" ex-situ sistematicamente esquecida.

As coleções biológicas, por meio de seu estudo e salvaguarda para o futuro, representam um dos primeiros e mais fundamentais estágios do conhecimento sobre a biodiversidade conferindo credibilidade ao produto final. Entretanto, o foco crescente na digitalização de acervos e no uso de ferramentas moleculares favoreceu indiretamente a melhoria em diversas etapas deste processo de produção de conhecimento além de promover novas perspectivas para a formação e atuação das novas gerações de taxonomistas (Wen et al. 20I5).

A crescente pressão sobre o conhecimento da biodiversidade deve-se à urgência do presente. Resulta da proporcional necessidade de gerar respostas para a também sem precedente crise que enfrentamos na qual os efeitos da superpopulação humana sobre os recursos do planeta não podem mais ser negligenciada. A tomada de consciência sobre a complexidade dos Serviços Ecossistêmicos' aponta para um cenário de cautela em virtude de seus impactos na economia global caso a saúde dos ecossistemas comprometa esta vital relação estabelecida com nosso meio.

O termo Antropoceno ${ }^{2}$ (Cruzen, 2002) vem sendo amplamente incorporado às narrativas dos museus de história natural (Dorfman, 2018) para designar a época em que vivemos. Representa uma tentativa de sublinhar a substantiva mudança na escala, agora geológica, das transformações exercidas pelos seres humanos. Já não falamos mais sobre crises locais ou extinções de espécies isoladas. A escala hoje é de tal magnitude que seus efeitos deixam registros no próprio planeta, como uma marca indelével de nossa passagem por aqui.

Segundo Latour (2015) mesmo que o termo represente talvez apenas mais uma estratégia de comunicação, seu uso reforça a necessidade do rompimento definitivo com a ilusória divisão entre natureza e humanidade. Em sua metáfora, Latour (20I5), nos faz aterrissar irremediavelmente neste planeta do qual somos parte indissociável. Ele nos remete, humanidade, inexoravelmente para o local de onde nunca partimos: a natureza. Diante das evidências acumuladas por séculos de investigação, a natureza não admite mais ser tratada como construção humana no sentido utópico. Este talvez seja o passo fundamental para que a mesma não se torne des-construção humana em um sentido distópico, ironicamente com efeitos deletérios sobre a humanidade. Para os museus

\footnotetext{
'Serviços Ecossistêmicos se refere aos bens e serviços obtidos dos ecossistemas, direta ou indiretamente são divididos em categorias: provisão(e.g. alimentos); regulação (e.g. controle do clima ; cultural (e.g. apreciação estética ) e de suporte (e. g. ciclo de nutrientes).

${ }^{2}$ Embora não seja ainda oficialmente reconhecido pela Geologia.
} 
em geral, o uso do tema Antropoceno representa também a oportunidade de abordagens integrativas em seus programas de comunicação. Ele inspira outras áreas além das tradicionais ciências da natureza com seu potencial de mobilização, criando um grande tema transversal a ser tratado em diversas tipologias de museus (Dorfman et al. 2018: pg 238).

Nossos impactos sobre o ambiente foram mais percebidos a princípio nas cercanias de onde vivemos. A vegetação nativa deu lugar às áreas cultivadas; as espécies de nosso convívio mudaram; os ambientes se transformaram para acomodar mais pessoas com suas necessidades de alimentação e reprodução forjando paisagens urbanas. Após a alteração de nossas cercanias chaga-nos a consciência de que também os oceanos (e, porque não, o espaço?) sofrem transformações profundas que são sentidas na prestação de um de seus principais serviços: o de provisão. Nossa espécie surgiu e coevoluiu em um determinado cenário de biodiversidade, do qual depende, e este se transforma rapidamente. Daí a necessidade de projetarmos os recursos marinhos que deixaremos para as futuras gerações por meio de seu uso sustentável ter assumido seu protagonismo nas esferas domésticas e internacionais nos últimos cinquenta anos.

O Brasil é signatário da Convenção Sobre a Diversidade Biológica, tratado internacional lançado em 1992 durante a ECO-92, a Conferência das Nações Unidas sobre o Meio Ambiente e Desenvolvimento, que visa a conservação e uso sustentável da biodiversidade e a justa distribuição dos benefícios provenientes de recursos biológicos ressaltando seu valor intrínseco. Como signatário, o país assumiu obrigações e para cumprí-las, delineia regulamentações que orientaram algumas políticas públicas.

Este novo cenário internacional ajudou a consolidar uma transformação que já estava em curso sobre o fluxo de material biológico e consequentemente sobre o crescimento das coleções em museus em diversos países. $O$ que historicamente era considerado território livre agora impõe as barreiras das novas legislações locais que precisam ser obedecidas para se ter acesso a organismos e para a realização de estudos sobre os mesmo. Criminalizamos a livre retirada de recursos naturais que durante séculos alimentaram as coleções e a pesquisa de museus centrais e o comércio de animais de países com poderes imperiais. Da mesma forma, a introdução de culturas de uma região em outra parte do planeta alterando distribuição de recursos econômicos na forma de produtos ou royalties passou a ser designada como biopirataria. Consequentemente observamos o crescimento e fortalecimento das coleções ditas periféricas que passam a receber mais material e coordenar parcerias internacionais em uma escala cada vez maior.

Parte das obrigações atuais do governo, além da legislação sobre recursos naturais, consiste na geração e disponibilização de informação sobre a biodiversidade brasileira. Estas resultaram em investimentos públicos para a digitalização e disponibilização online de acervos biológicos e também de literatura fundamental para a pesquisa em taxonomia. (e.g. SIBBr - Sistema de Informação sobre a Biodiversidade Brasileira e GBIF - The Global Biodiversity Information Facility, que desde 2012 conta com a participação do Brasil).

Mais recentemente, em 2012, foi lançada a Plataforma Intergovernamental da Biodiversidade e Serviços Ecossistêmicos (IPBES), nos moldes do Painel Intergovernamental de Mudança do Clima (IPCC), de 1988, que tem como parte de seus objetivos 
“...envolver governos, universidades, organizações científicas, organizações não governamentais, povos indígenas e populações tradicionais para, sintetizar, revisar e avaliar criticamente as informações e conhecimentos relevantes sobre biodiversidade e qualidade de vida das pessoas." (BPBES, 2017)

Estas iniciativas tem impactado o gerenciamento das coleções no MZUSP e em outras similares em nosso país e no mundo apontando áreas prioritárias de financiamento público.A disponibilização de dados online, uma das atividades priorizadas, é vista com certo ceticismo pela comunidade acadêmica que questiona o uso que será feito desta informação. Dados sobre o registro de material em coleções são bastante técnicos e podem ser considerados problemáticos sem a avaliação crítica de um especialista. Ou seja, o produto final, para ser usado como fonte de informação confiável perde potencialmente seu valor sem a apreciação de um iniciado. Isto nos remete de volta ao início da cadeia da geração de conhecimento, aos seus primeiros passos, e à centralidade do estudo especializado das coleções biológicas neste processo.

Aos olhos de um leigo, a atribuição de um nome a uma entidade biológica como espécie, pode parecer trivial. Ao contrário, dependendo do grupo com o qual se trabalha a tarefa pode ser extremamente difícil e penosa (Carvalho et al. 2007). Ela requer estudo detalhado de todas as entidades similares conhecidas, daí a importância de acesso rápido à literatura e ao material depositado em coleções biológicas. Muitas vezes as informações relevantes aos taxonomistas não são as que serão disponibilizadas online. Por existir uma grande carência de especialistas em diversos grupos de animais capazes de produzir dados precisos sobre os espécimes garantindo informação acurada sobre o material depositado nos museus, ocorre inexatidão de uma parte considerável na atribuição de nomes e localidades precisas. Isto favorece que haja uma margem considerável de erros inerente ao processo, o que é claramente compreendido pelos especialistas. Por outro lado, a digitalização é vista com grande otimismo pelos museus. Representa um salto qualitativo sem precedentes para o gerenciamento e salvaguarda das coleções.

A qualidade dos dados de uma coleção depende em última instância da atualidade e qualidade do esforço da último pesquisador que se debruçou sobre a mesma, identificando o material e corrigindo suas informações. Como parte substancial das coleções biológicas nunca foram tratadas por especialistas este material permanece como matéria bruta de pesquisa para as futuras gerações de novos taxonomistas (Kemp, 2017). Cabe ressaltar que as coleções que recebem o olhar de especialistas, são consideradas as de maior valor agregado o que reflete também em sua salvaguarda. Isto torna ainda mais crítica a ameaça atual à biodiversidade no que tange aos bancos de informação ex-situ (Funk, 20I4). Existem poucos profissionais qualificados em relação à demanda que nem sempre resulta em oportunidade de empregos.

A urgência na digitalização de acervos, seus dados e bibliografia reflete ainda uma das características históricas da pesquisa sobre a diversidade biológica que é a sua "globalização". O esforço em rede de conhecimento sempre foi internacionalizado uma vez que a biodiversidade e o conhecimento não reconhecem as barreiras políticas impostas pelos seres humanos. 


\section{Biodiversidade oceânica}

Os oceanos representam o maior bioma cobrindo $71 \%$ da superfície do planeta com uma área aproximada de $36 \mathrm{I}$ milhões de quilômetros quadrados e volume de cerca de $1,4 \mathrm{~km}^{3}$ (Jaume e Duarte, 2006). Sua superlativa dimensão não supera sua importância histórica como o sendo o berço da vida em nosso planeta. Este ambiente abriga o maior número de filos animais, muitos exclusivos, o que pode ser tomado como uma medida de diversidade além do tradicional número de espécies. Ainda assim, é uma área do planeta que permanece no século $\mathrm{XXI}$ como um dos últimos redutos do que poderíamos chamar ironicamente de terra incognita, principalmente no que diz respeito aos seus habitantes.

Mesmo que antiga (Roberts, 2007), a interferência humana nos oceanos recebeu destaque tardio em comparação a outros ecossistemas. Os efeitos da sobre-pesca, da poluição3, das mudanças climáticas, da introdução de espécies exóticas são sentidos por toda a extensão dos oceanos e representam grave ameaça sobre a manutenção de seus serviços ecossistêmicos o que justificou a partir do século $X X$ uma grande mobilização internacional em torno do tema.

Em meados do século $X X$ houve uma crescente preocupação com o despejo de lixo nos oceanos. Em 1972, o que ficou conhecido como a convenção de Londres (The Convention on the Prevention of Marine Pollution by Dumping of Wastes and Other Matter) representou o primeiro esforço internacional para proteção do ambiente marinho. Ratificada pelos EUA em 1974, ela entrou em vigor em 1975 e hoje conta com cerca de 80 países signatários. Em seguida, em 1996, o Protocolo de Londres representou uma atualização da Convenção, vigorando desde 2006. O Protocolo conta com 50 signatários tendo os EUA ficado de fora.

Em 1992, a preocupação com os oceanos na Conferência das Nações Unidas no Rio de Janeiro, está documentada no capítulo 17 da Agenda 2I, que reforça a necessidade de preservação e do uso sustentável dos recursos marinhos. Em 1995 foi criada a Comissão Mundial Independente sobre os Oceanos, presidida pelo ex-Primeiro Ministro de Portugal, Mario Soares.A Comissão apresentou o relatório The Ocean... our Future em 1998 coincidindo com a inauguração do Oceanário de Lisboa no que ficou conhecido como o ano internacional do Oceanos pela ONU.A abertura do Oceanário vem de encontro a uma das metas no que tange a sensibilização do público para o tema.Aconteceu no país que iniciou o processo de globalização a partir da exploração do mesmo. O Oceanário de Lisboa representa o principal equipamento com esta finalidade no continente europeu, recebendo um grande número de visitantes para sua coleção de animais vivos.

Entra em vigor em 1994 a Convenção sobre o Direito do Mar da ONU, tratado internacional que regulamenta o uso dos mares fora do escopo territorial nacional, que governa sobre, entre outras coisas, o espaço marítimo com a sua delimitação, o controle ambiental e as atividades econômicas e de pesquisa.

Em 2003, foi criada a rede interagências da ONU sobre oceanos e ambientes marinhos, mais tarde chamada de ONU-Oceanos que se reuniu pela primeira vez em 2005 no que constitui uma força tarefa com o intuito de, entre outras coisas, fornecer informação atualizada sobre a implementação do Direito do Mar.

No âmbito da Convenção sobre a Diversidade Biológica foi estabelecido o que ficou conhecido como Metas de Aichi, no encontro realizado em Nagoya na $10^{a}$ Conferência das Partes, em 2010. As Metas de Aichi orientam os países

\footnotetext{
${ }^{3} \mathrm{~A}$ estimativa mais recente informa que o lixo flutuante no Pacífico já alcançou cerca de 79 mil toneladas de plástico em cerca de I,6 milhões de km2 (Lebreton et al. 2018).
} 
signatários em termos de prazos e objetivos a serem cumpridos até 2050. Dentre elas, estabelece-se a percentagem mínima de áreas protegidas para os diversos ecossistemas. Acabamos de assistir o empenho do governo brasileiro em cumprir a sua meta de proteção de áreas marinhas com a criação do mosaico de áreas protegidas representadas pelos arquipélagos de Trindade e São Pedro e São Paulo ${ }^{4}$. Neste ato, o país aumentou para cerca de $25 \%$ a extensão de sua área marinha protegida.

Em 2015 a Assembleia Geral da Nações Unidas aprova a Agenda 2030 com 17 Objetivos para o Desenvolvimento Sustentável (ODS) a serem perseguidos pelos países signatários. O ODS I4, trata da vida marinha e impõe metas conservacionistas e mitigatórias para os países membros.

Para avançar na implementação do ODS 14, em 2017 a ONU promoveu a Conferência sobre Oceanos em sua sede em Nova lorque.A conferência coincidiu com o Dia Mundial do Oceanos, 8 de junho, idealizado em 1992 nos moldes do já tradicional Dia Mundial do Meio Ambiente, 5 de junho, como grande data de mobilização para o tema.

Um passo importante para o inventário da vida marinha foi o Census of Marine Life, trabalho que reuniu durante uma década, de 2000 a 2010, o esforço de 2.700 pesquisadores de 80 países. A publicação de seus primeiros dados em 2010 , representou uma importante atualização sobre o estado da arte sobre o conhecimento da diversidade da vida marinha.

Em linhas gerais, o censo aponta que a biodiversidade marinha é maior, mais conectada e impactada pelas ações humanas do que antes previsto (Snelgrove, 2010). Considerando a estimativa da época de cerca de 230.000 espécies conhecidas $^{5}$, os pesquisadores do Censu projetavam a existência de cerca de I.4 milhões de espécies vivendo nos oceanos. Isto significa que nosso desconhecimento sobre a biodiversidade nos mares pode alcançar a taxa de $80 \%$ das espécies existentes. Esta alarmante taxa de desconhecimento se torna ainda mais crítica diante da pressão que a sobre-pesca, poluição, introdução de espécies exóticas e efeitos das mudanças climáticas exercem sobre este ambiente (Costello et al. 20I0).

Nos museus tradicionais de história natural a representatividade da diversidade oceânica em suas coleções esteve, de um modo geral, atrelada a oportunidades de prospecção neste ambiente. $O$ principal fator de limitação de acesso aos oceanos seria o econômico e tecnológico já que sua prospecção implica no uso de aparatos mais caros (e. g. barcos equipados e suas equipes, equipamentos de mergulho, etc) do que exige a exploração do meio terrestre. Isto é ainda mais relevante se considerarmos que a maior extensão dos oceanos está abaixo de $200 \mathrm{~m}$ de profundidade (Duarte, 2006).

Estamos nos preparando para entrar na década das Nações Unidas para os oceanos (de 2021-2030) e podemos esperar uma série de iniciativas voltadas para a produção de conhecimento e preservação da vida marinha. Estas iniciativas refletem fortemente sobre o financiamento público e privado da pesquisa sobre biodiversidade e fomentam os programas voltados ao público. Com maior facilidade de obtenção de bolsas, auxílios e até patrocínio por meio de empresas que exploram recursos marinhos, o tema certamente refletirá nos museus de história natural de diversas formas.

A presente contribuição buscou traçar em linhas gerais a relação do Museu de Zoologia da Universidade de São Paulo com a pesquisa sobre organis-

${ }^{4}$ Decreto 9.312 de 19 de março de 2018.

${ }^{5}$ Dados mais atuais indicam 243.000 (Costello e Chaudhary, 2017). 
mos oceânicos, incluindo aqui as aves e outros organismos terrestres que vivem associados ao ambiente marinho, por meio de suas coleções e o impacto destas nas atividades de extroversão.

\section{Navegando nas Águas do Museu de Zoologia da Universidade de São Paulo (MZUSP)}

Este não se pretende um estudo exaustivo sobre as coleções de animais marinhos em nossa instituição mas foca sobre a percepção da relevância do tema aos olhos de nossos curadores ativos. Busquei apresentar a pesquisa e as coleções marinhas no Museu de Zoologia da Universidade de São Paulo por meio de entrevistas com alguns de seus curadores.

As seguintes perguntas foram formuladas e encaminhadas aos entrevistados:

I) Qual a representatividade da pesquisa em torno do tema "ambiente marinho" no seu laboratório em termos de projetos, orientações e acervo; 2) A linha já era ativa quando ingressou no MZUSP; 3) Quais foram os precursores (atores) institucionais e seu legado; 4) A linha ajudou a fomentar outras coleções provenientes de projetos em curso? Quais? 5) Quais as regiões em que realiza pesquisa e abrangência das coleções "oceânicas" do seu grupo de estudo; 6) Quais os projetos e resultados relevantes; 7) Quais os principais desafios para a pesquisa e curadoria na área; 8); Quais os principais desafios institucionais para trabalhar com o tema.

O questionário foi respondido pelos Professores Naércio A. Menezes e Aléssio Datovo (Ictiologia); Luis Fábio Silveira (Ornitologia \& Mastozoologia); Luiz Simone (Malacologia); Marcelo Fukuda (Invertbrados Marinhos), Marcos Tavares (Carcinologia) e Hussam Zaher (Herpetologia). $O$ questionário não foi formalmente apresentado à Entomologia, que embora abrigue uma coleção importante de Diptera (moscas e mosquitos) das ilhas do Hawaii, não apresenta projetos ativos com o tema.

As respostas foram obtidas por meio de conversas informais gravadas, realizadas nos dois primeiros meses de 2018. Elas não serão transcritas aqui, mas foram usadas para ilustrar as diversas formas de atuação na pesquisa sobre a biodiversidade oceânica nos diversos laboratórios do MZUSP na percepção de seus curadores. As conversas também buscaram elucidar um padrão sobre a formação de coleções relacionadas a este ambiente ao longo da história de nossa instituição. Por último, abordarei como a questão dos oceanos aparece retratada em nosso Programa de Comunicação Museológica que foi renovado em 2014 por ocasião da reformulação da exposição de longa duração inaugurada no segundo semestre de 2015 com o título: Biodiversidade, conhecer para preservar.

\section{Nosso mar de histórias: uma antologia de espécies já desaparecidas}

O Museu de Zoologia da Universidade de São Paulo (MZUSP) abriga uma coleção centenária que já esteve sob a égide de distintas instituições ao longo de sua história. Coleções privadas do século XIX (Carvalho, 20 I4; CarvaIho, 20I5) que foram parar nas mãos do estado de São Paulo formaram o núcleo inicial do Museu Paulista fundado em 1894.As coleções zoológicas nesta instituição prosperaram (Grola et al. 2016) sob a direção do naturalista alemão Herman von lhering (I850 - 1930) que esteve à frente do Museu Paulista de 1894 até 1916 conferindo a este um caráter de instituição voltada à História Natural. 
No final da década de 1930, a então seção de Zoologia do Museu Paulista, já sob a Direção de Affonso d'Escrangnolle Taunay, tornou-se Departamento de Zoologia da Secretaria de Agricultura, Indústria e Comércio do Estado de São Paulo (Lopes, 1997). Como tal, recebeu uma sede própria em 1940 construída para abrigar suas coleções e laboratórios. Em 1969, o Departamento de Zoologia foi incorporado à Universidade de São Paulo assumindo sua atual feição de museu universitário.

Desde o seu início, a pesquisa no MZUSP esteve focada na taxonomia, sistemática e biogeografia de animas neotropicais, com algumas abordagens ecológicas. Para tais estudos o ambiente em que os organismos vivem é menos relevante do que as linhagens evolutivas às quais estão vinculados. Por esta razão, historicamente, as coleções do MZUSP cresceram principalmente em função da atuação dos pesquisadores vinculados a ele e das oportunidades por eles criadas.

O MZUSP conta, em 2018, com 12 docentes ativos e I professor sênior. Suas coleções estão distribuídas em diversos Serviços, como consta em seu organograma: Entomologia, Vertebrados, Invertebrados e Divulgação e Exposições. No Serviço de Entomologia atuam 5 docentes em diferentes grupos taxonômicos (Diptera, Coleoptera, Lepidoptera, Isoptera e Hymenoptera). No Serviço de Vertebrados temos 5 docentes, sendo 3 ictiólogos, I herpetólogo e I ornitólogo que acumula a curadoria da Matozoologia. No Serviço de Invertebrados temos I carcinólogo; I malacólogo e I curador recentemente contratado (janeiro de 2018) para a crescente coleção de Invertebrados Marinhos. No Serviço de Exposições e Divulgação Científica I docente é responsável pela coleção museográfica.

\section{Os peixes: puxando a brasa para a minha sardinha}

As parcerias institucionais foram apontadas por todos como sendo responsáveis pelo principal meio de entrada sistemática de itens marinhos nas diversas coleções. A parceria que existiu entre o Instituto Oceanográfico da USP e o MZUSP durante as expedições do Navio Professor Besnard ao longo da costa brasileira no final da década de 1960 e início da década de 1970 (Menezes et al. 1997) merece especial atenção.

O MZUSP tornou-se o depositário de grande quantidade de material destas expedições, principalmente dos peixes ósseos, em virtude da presença em nossa instituição dos professores Naércio Menezes e José Lima de Figueiredo, especialistas no grupo. Este momento marcou o início do aumento considerável da coleção de peixes marinhos, antes incipiente. Hoje, essa é uma das coleções mais importantes para estudos sistemáticos dos grupos que ocorrem no Atlântico Sul. Estas coleções fomentaram a pesquisa e a orientação de alunos de pós-graduação que agora atuam em outras instituições universitárias no país.

No caso dos peixes especificamente a riqueza de espécies nas diversas bacias hidrográficas brasileiras, a maior do mundo, torna a ictiofauna de água-doce um ponto focal da pesquisa em sistemática no Brasil drenando, ao longo tempo, maior aporte de recursos financeiros e humanos. A este fato, soma-se a enorme pressão em virtude do impacto sofrido por nossos rios em um longo histórico de interferências em seus leitos pela poluição, sobre-pesca, introdução de espécies exóticas e inúmeras barragens que interferiram de forma dramática na ictiofauna (Nogueira et al. 2010 e Alho et al. 2015).

Ainda assim, o ambiente marinho foi foco de pesquisas da ictiologia do MZUSP desde a estruturação deste Laboratório com a contratação dos professores acima 
citados. Ao longo do tempo, a parceria com o IO foi perdendo sua relevância, principalmente com a aposentadoria do Prof. José Lima de Figueiredo. Entretanto, as coleções que se encontram no MZUSP são reconhecidamente necessárias para lidar com as questões sobre a sistemática do e biogeografia deste grupo.

Uma aspecto mencionado pelo Prof. Naércio Menezes é o fato de que como os oceanos não apresentam barreiras evidentes à distribuição dos organismos, estudos clássicos consideravam que as espécies do hemisfério norte eram as mesmas do hemisfério sul. Esta informação vem sendo testada em pesquisas recentes que dependem de amostras significativas obtidas por toda a extensão da ocorrência dos peixes amplamente distribuídos. Estas amostras estão dispersas em museus de diversos países e continentes, dificultando e encarecendo ainda mais a pesquisa sobre o grupo. Ou seja, para se estabelecer com segurança os limites das espécies que ocorrem nos oceanos o pesquisador precisa visitar as coleções de diversos museus. Um fato que reforça a necessidade da consulta à coleção do MZUSP, obrigatória para o estudo das espécies ou populações que frequentam o Atlântico Sul. Para Menezes, estudos recentes usando técnicas moleculares não só permitem a formulação de novas questões sobre a história evolutiva destes grupos, como fornecem novas respostas às antigas. A incorporação de dados moleculares aos estudos tradicionais foi apontada como um grande desafio para a pesquisa em sistemática de peixes marinhos desenvolvida na casa.

Em 20I4, a vaga do professor aposentado José Lima de Figueiredo foi preenchida com a contratação de um novo docente que trabalha com estudos morfológicos para elucidar a história evolutiva dos peixes. Para ele, como para os sistematas em geral, não existe distinção em relação ao ambiente em que os peixes ocorrem, mas sim, às linhagens evolutivas às quais eles pertencem. Ele reforça que apesar da sistemática de peixes ser bem estudada em relação a outros grupos animais, as questões mais interessantes atualmente estão justamente sobre um grande grupo de peixes, quase que exclusivamente marinhos, os Percomorpha, que atraem e deverão atrair muitos novos pesquisadores nos próximos tempos.

\section{Os demais vertebrados: nem tudo que cai na rede é peixe}

Quando pensamos em oceanos, os peixes aparecem como um de seus recursos mais notórios. Representam uma importante proporção da diversidade de vertebrados em ambientes marinhos, também respondem como importante fonte de alimento e recurso pesqueiro. Por esta razão, o grupo sofre grandes impactos relacionados à sobre-pesca, degradação de ambientes naturais por poluição (como ocorre em estuários) ou mudanças climáticas que promovem por exemplo a acidificação dos oceanos e branqueamento dos recifes de corais, importante local para o desenvolvimento de diversas espécies marinhas. Mas a sobre-pesca afeta igualmente outros organismos que são consumidos como frutos-do-mar exercendo enorme pressão sobre suas populações, principalmente em áreas muito populosas ou muito procuradas por turistas.

Chama a atenção o relato do curador da Ornitologia, Prof. Luis Fabio Silveira, que menciona a captura acidental de aves marinhas (albatrozes e petréis) como principal causa da entrada destas aves em nossas coleções nos últimos 10 anos. Ao utilizarem estruturas como espinhéis e iscas, os pescadores acabam capturando acidentalmente uma grande quantidade de aves que morre afogada. A sobre-pesca tornou-se a principal ameaça para estes grupos e vem sendo monitorada e regulamentada na tentativa de reverter este fenômeno que é global.

A coleção de Ornitologia do MZUSP não teve ao longo de sua história ne- 
nhum projeto específico que tenha resultados em coletas sistemáticas de aves marinhas em ambientes costeiros ou oceânicos. Por outro lado, a característica da incorporação de acervo destes grupos, que por ser incidental não agrega dados e estratégias de coleta importantes para a pesquisa sistemática, agrega à mesma uma importância histórica singular. Por ser muito antiga em relação a outras coleções brasileiras, com registros que datam do final do século XIX, ela tem sido requisitada para estudos que usam isótopos estáveis em abordagens ecológicas e biogeográficas.

Recentemente, a coleção de mamíferos ficou sem um curador e Silveira hoje responde também por sua curadoria. Silveira informa que a relevância da nossa coleção é principalmente histórica já que o grupo nunca foi objeto de pesquisa na casa. Ressalta ainda os desafios curatoriais específicos da coleção em virtude do tamanho dos mamíferos marinhos e mencionando a presença em nossa instituição, desde a época de Herman von lhering, de um exemplar de baleia azul, o maior vertebrado vivente no planeta.

Ainda no âmbito dos vertebrados o Prof. Hussam Zaher, curador da Herpetologia, informa que além de alguns poucos exemplares históricos das 5 espécies de tartarugas marinhas que desovam no Brasil, das 7 que são conhecidas. As coleções abrigam ainda alguns lotes de serpentes que ocorrem em ilhas oceânicas.

\section{Caranguejo só é peixe lá no fundo da maré}

O curador da coleção de Crustáceos, Prof. Marcos Tavares, ex-diretor do MZUSP, ressalta o papel central que Herman von lhering teve em fomentar os primórdios de nossas coleções por seu interesse em organismos marinhos. Pondera que se por um lado, suas conexões internacionais significaram o envio de material relevante para outros países, por outro, resultaram em oportunidades únicas para as nossas coleções.

Uma outra contribuição de lhering que merece ser lembrada foi a contratação de naturalistas como Hermann Lüderwaldt (I865-1934) que realizou estudos coletas e estudos em manguezais de Santos. Lüderwaltd teve vários organismos descritos em sua homenagem mas um deles vale ser mencionado. Descrita por Mary Rathbun (1860-1943) carcinóloga da Smithsonian, Cancer luerdwaldti foi descrita em 1930 a partir de material coletado no Brasil e enviado por Lüderwaldt para a instituição americana. Mais tarde a espécie foi sinonimizada quando descobriram se tratar de uma espécie de crustáceo europeia Cancer pagurus, descrita por Lineu e introduzida inadvertidamente no Brasil.

Um exemplo sobre as relações internacionais dos primeiros curadores é a coleção estudada por Georg O. Sars (I837 - 1927), um dos fundadores da biologia marinha norueguesa depositada no MZUSP. Ihering coletava amostras de areia que remetia a Sars. Este promovia o desenvolvimento dos organismos ali contidos e os identificava retornando a Ihering parte do material. Hoje, esta coleção tem uma grande importância histórica assinalando a contribuição de Sars para diversas instituições fora da Noruega.

Tavares relata que na década de 1960 um grupo de jovens pesquisadores ingressaram no MZUSP e entre eles figurava o carcinólogo aposentado Prof. Gustavo Schmidt de Melo. Isto garantiu a continuidade dos estudos de crustáceos na instituição. O Prof. Melo deixou o legado de uma coleção com cerca de I 3.000 lotes correspondendo a meio milhão de exemplares. As parcerias com os navios oceanográficos Almirante Saldanha, da Marinha e, mais tarde, o Professor Besnard do Instituto Oceanográfico representaram momentos emblemáti- 
cos para o crescimento das coleções de crustáceos neste período.

Hoje, a coleção de crustáceos do MZUSP, uma das maiores para o grupo no país, conta com 40.000 registros e cerca 25.000 lotes a serem registrados ilustrando o crescimento exponencial que apresentou nos últimos anos.

Segundo Tavares, a mudança no foco da pesquisa oceanográfica dos padrões da biodiversidade marinha para os processos que ocorrem nos oceanos como ciclos de matérias e sobre os efeitos dos oceanos sobre o clima promoveram com o tempo uma diminuição na intensidade destas parcerias. As estratégias de amostragem realizadas pelas equipes embarcadas nestes navios divergiram das estratégias usadas para os estudos taxonômicos.

Tavares com um logo histórico em pesquisa oceanográfica antes de seu ingresso no MZUSP foi responsável pela incorporação de parte importante das coleções coligidas por ele na época em que trabalhou na Universidade Santa Úrsula, no Rio de Janeiro.

Como instituição fiel depositária credenciada pelo Conselho de Gestão do Patrimônio Genético, Tavares ressalta a importância das doações de material e coleções ao museu. As doações são feitas tanto por empresas, e aqui destacam-se as empresas petroleiras de coleções geradas por seus estudos de impacto ambiental e as de pesquisadores vinculados a departamentos universitários. O reconhecimento da crescente profissionalização no gerenciamento de seus acervos, tem garantido um grande aporte de material ao MZUSP reforçando também as coleções de outros grupos marinhos.

A entrada de Tavares no MZUSP também influenciou no enorme crescimento da coleção de Invertebrados Marinhos. O material, além de coletado sistematicamente em suas expedições também foi agregado em suas parcerias que trouxeram pesquisadores de diversos grupos para estudar estas coleções. Adicionalmente, por meio de projetos com a Petrobras, viabilizou a construção de uma área específica para abrigar o novo Laboratório de Invertebrados Marinhos que ajudou a equipar com lupas e armários para as coleções.

Com uma abrangência da Guiana Francesa ao Uruguai, a coleção de carcinologia para os grupos marinhos é incontornável para os estudos carcinológicos, nas palavras de seu curador. Com pesquisas ativas sobre composição faunística em ilhas oceânicas como Trindade, e em taxonomia de Decapoda e estudos evolutivos dos caranguejos, a coleção continua a crescer.

O maior desafio para a curadoria do grupo está na variação em escala de tamanho que os crustáceos apresentam. Dos diminutos copépodos ( $1 \mathrm{~mm}$ a $5 \mathrm{~mm}$ ) aos caranguejos gigantes (com mais de $3 \mathrm{~m}$ de envergadura), esses animais exigem técnicas de preparo e armazenamento totalmente distintas.

Um desafio apontado por Tavares é o das amostragens e conhecimento da diversidade do Atlântico Sul. Como marco para as coletas em águas profundas, para o hemisfério sul também, cita a expedição oceanográfica do final do século XIX do HMS Challenger. Tavares pondera que nesta lendária expedição foram amostrados apenas quatro pontos nesta região. Em 1987, a exploração das águas profundas brasileiras foi retomada pela expedição MD55 Brasil//987. Tavares participou das coletas a bordo do navio Marion Dufresne em um projeto que envolveu a Universidade Santa Úrsula do Rio de Janeiro e o Museu Nacional de História Natural de Paris. Outra importante iniciativa foi o Programa ReviZEE, promovido pelo Ministério do Meio Ambiente com vistas à cumprir suas obriga-

6Programa de Avaliação do Potencial Sustentável de Recursos Vivos na Zona Econômica Exclusiva do Ministério do Meio Ambiente. 
ções em virtude do tratado Direito do Mar (acima citado) que também resultou na geração de uma quantidade relevante de acervo coligido em profundidades de até 5.155 metros.

O curador ressalta o caráter recente e ainda esporádico destas coleções fundamentais para estimarmos a diversidade de invertebrados marinhos em nosso país. Um agravante é que as espécies marinhas foram em geral identificadas como animais que ocorrem no hemisfério norte e tidas como amplamente distribuídas. Criou-se uma tradição de atribuição de nomes conhecidos para populações pouco ou não amostradas do hemisfério sul.A dificuldade de amostragem e disponibilidade de material comparativo alimenta o grande desconhecimento que ainda permanece sobre estes grupos, principalmente em ambientes de profundidade que exigem tecnologia custosa para sua exploração.

\section{Na boca do polvo - do mar para a mesa}

No caso da Malacologia, temos a já mencionada contribuição do primeiro diretor do Museu Paulista, o naturalista Herman von Ihering que tinha nos moluscos o seu foco de estudos. O Prof. Luiz Simone, atual curador da coleção, lamenta que os lotes provenientes da coleção de Ihering, que receberam numeração abaixo de 10.000 no MZUSP, infelizmente ou não existem ou se encontram em estado precário de conservação. Segundo o Simone, o legado de lhering foi mais inovador e relevante para outras áreas do conhecimento do que para a Malacologia, assunto que pretende abordar em uma futura publicação.

A despeito deste início pouco promissor, o curador informa que ao ingressar no MZUSP o registro da coleção de moluscos estava em torno dos 30.000 lotes. Antes dele, outro malacólogo havia trabalhado na Malacologia do MZUSP. Como membro da geração de biólogos que ingressaram no museu na década de 1960, como mencionado por Tavares acima, José Luis Moreira Leme respondeu pela coleção de moluscos com foco nos moluscos terrestres.

Desde então a coleção cresceu de forma considerável e hoje já são I 40.000 lotes tornando-a a coleção mais importante do Brasil para o grupo. $O$ expressivo crescimento se deve principalmente a parcerias institucionais, aquisição de coleções e coletas sistemáticas na costa brasileira e em outros locais como ilhas oceânicas e, mais raramente, em outros países.

Simone, ressalta as estreitas relações institucionais que promoveram durante muito tempo o depósito das coleções formadas pelo IO-USP nas diversas coleções do museu. Como parceiros institucionais relevantes Simone cita, além do IO, o Museu Nacional de História Natural de Paris, que realizou coletas estratégicas no litoral brasileiro. As coletas que foram realizadas até $200 \mathrm{~m}$ de profundidade, resultaram em coleções importantes que foram, em um primeiro momento, integralmente transferidas para Paris. Apesar de $80 \%$ das espécies de moluscos conhecidas serem encontradas até $5 \mathrm{~m}$ de profundidade, é abaixo disso que a informação se torna rarefeita pela dificuldade de acesso. Depois de longo período sem especialistas para identificar o material depositado em Paris, o mesmo será parcialmente depositado no MZUSP em troca da identificação e descrição das novas espécies que abundam nesta preciosa coleção. Isto permite um aumento considerável da abrangência de nossas coleções, não só em termos de novos táxons mas também em termos de novas áreas amostradas.

Ainda que não exatamente no contexto de parcerias institucionais, Simone informa que os projetos patrocinados pela Petrobras também têm contribuído para o implemento de nossas coleções da Malacologia. 
Simone estima que o conhecimento dos moluscos marinhos esteja em torno de $50 \%$ das espécies existentes. Ressalta ainda que o fenômeno acima abordado para os peixes e crustáceos, em relação à distribuição das espécies e sua correta delimitação, também se aplica aos moluscos. Cita o caso da ostra, amplamente consumida no Brasil que ainda não havia sido descrita. Isto ocorre porque o nome que era atribuído à espécie, Cassostrea rizophorae estava vinculado a material descrito para o Caribe e considerado amplamente distribuído. Durante muito tempo acreditou-se que esta seria a espécie consumida no Brasil. Esta hipótese só foi testada recentemente por Simone e colaboradores (Amaral e Simone, 20I4) que fizeram estudos comparativos usando material disponível na coleção. Os autores concluíram que as ostras que consumimos são de duas espécies novas Cassostrea brasiliana e Cassostrea mangle. Este exemplo é contado na nova exposição de longa-duração como exemplo dos impactos de nossa pesquisa em assuntos mais mundanos. $O$ limite correto entre espécies distintas e a precisa delimitação de sua área de ocorrência é parte da informação relevante a ser levada em conta para avaliação do grau de ameaça a que uma determinada espécie está sujeita e, desta forma, ajudar na elaboração de medidas de preservação da mesma.

Como grandes desafios para a pesquisa, Simone aponta principalmente a introdução de espécies exóticas. Com o aumento de registros de novas ocorrências de espécies de outras regiões, o trabalho do sistemata torna-se ainda mais complexo. Para identificação de material é preciso agora comparar com espécies de outras localidades antes de determinar se pode se tratar de uma nova espécie local ou não. Além disso, ressalta o impacto que as introduções exercem sobre os ambientes naturais e cita o caso das duas espécies de coral-sol que vem alterando radicalmente ambientes marinhos litorâneos no Brasil.

\section{Invertebrados Marinhos: muita maré para pouco marinheiro}

A principal evidência de que o ambiente marinho representa uma importante fronteira para o conhecimento da biodiversidade e para a pesquisa em nossa instituição é a recente contratação de um curador para o novo Laboratório de Invertebrados Marinhos.

Usamos o termo Invertebrados Marinhos no MZUSP, para designar todos os animais não-cordados, exceto Crustáceos e Moluscos que já são contemplados com curadoria específica. Isto significa, em termos de biodiversidade, que esta coleção abrange diversos filos de animais pouco conhecidos representado uma parcela significativa de diversidade animal a ser estudada.

Com um longo histórico institucional que começa no início do século $X X$ com a contribuição de Aaron Treadwell (1866-1947), afiliado ao Museu Americano de História Natural em Nova lorque. Treadwell foi um especialista em Polycheata com uma forte contribuição no estudo de diversas coleções incluindo a do Museu Paulista.

Como mencionado acima esta coleção cresceu muito no século $X X I$, em número de lotes e importância institucional, como consequência das pesquisas e coletas ativas dos Laboratórios de Carcinologia e de Malacologia. $O$ que o que antes se traduzia em alguns armários nos corredores do MZUSP, tornou-se, uma coleção estruturada, com espaço próprio e corpo técnico dedicado e conta agora com seu primeiro curador, especialista em Polychaeta (anelídeos aquáticos), Prof. Marcelo Fukuda.

Uma outra forma importante de aumento desta coleção tem sido a doa- 
ção de coleções formadas por outros pesquisadores para o MZUSP. Um exemplo foi a transferência da importante coleção de equinodermas do Prof. Luis Roberto Tommasi, ex-diretor do IO, para o novo Laboratório de Invertebrados Marinhos do MZUSP.

Segundo Fukuda, o principal desafio para o estudo desta coleção, além da falta de especialistas para os diversos grupos que ela contempla, é o espaço que será necessário para abrigá-la após uma triagem do material ainda que grosseira designando famílias e não espécies. Hoje, o material que se encontra armazenado em grandes lotes coletivos tem o potencial de no mínimo vir a ocupar dezenas de outros demandando local adequado para seu armazenamento.

Outro desafio mencionado está na preservação de alguns animais de constituição muito delicada que requerem técnicas de preparação em lâminas para a preservação de suas partes gerando uma grande perda de informação sobre a forma dos mesmos durante o processo.

Fukuda reconhece que a coleção abriga material suficiente para alimentar a carreira de algumas gerações de taxonomistas e que com o desenvolvimento da pesquisa na casa, a tendência é que ela aumente em uma taxa ainda mais significativa.

\section{Conhecer para preservar e não morrer na praia}

Durante o esforço coletivo de reestruturação da exposição de longa-duração do MZUSP aproveitamos para renovar o Programa de Comunicação Museológica (PCM) da instituição alinhavando aos valores, conceitos e estratégias que seriam priorizados em nossas atividades de extroversão. Além do já tradicional foco na biodiversidade por meio da abordagem de nosso acervo e pesquisa sobre animais, a comunidade reforçou a necessidade de que a biodiversidade fosse apresentada e contexto evolutivo e que os seres humanos fossem colocados em contexto: como parte do processo evolutivo e atores de transformação ambiental.

Também ficou estabelecido que a exposição de longa-duração representaria nosso eixo condutor que, aliado a programas específicos voltados a diferentes parcelas de nosso público, nos auxiliaria a alcançar objetivos específicos e responder a novas necessidades de comunicação detectadas ao longo do tempo.

Como instituição universitária, nosso Programa de Comunicação Museológica está fortemente vinculado à pesquisa em torno de nosso acervo e esta foi a tônica da consulta feita à comunidade durante a elaboração do projeto em suas diversas fases.

Esta abordagem resultou na apresentação da história da biodiversidade com a introdução ao conceito de Antropoceno. Em seguida apresentamos as paisagens naturais de nosso país por meio de dioramas estilizados. Usamos técnicas adaptadas ao século XXI com fotografias em alta resolução impressas sobre tecidos translúcidos com os animais interpostos para retratar estas paisagens. Neste setor, os oceanos aparecem figurados ao lado dos ambientes de água-doce e demais biomas terrestres (Fig. I).

Incluímos ainda os dois ecossistemas oficialmente reconhecidos resultantes das transformações provocadas por ações humanas: os ecossistemas urbanos por meio de uma foto aérea da cidade de São Paulo em alta resolução, e os ecossistemas de áreas cultivadas por meio de foto aérea das mesmas. Neste setor apresentamos um diagrama ilustrando a origem e dispersão de Homo sapiens. Após a apresentação dos diversos ecossistemas, introduzimos o conceito 


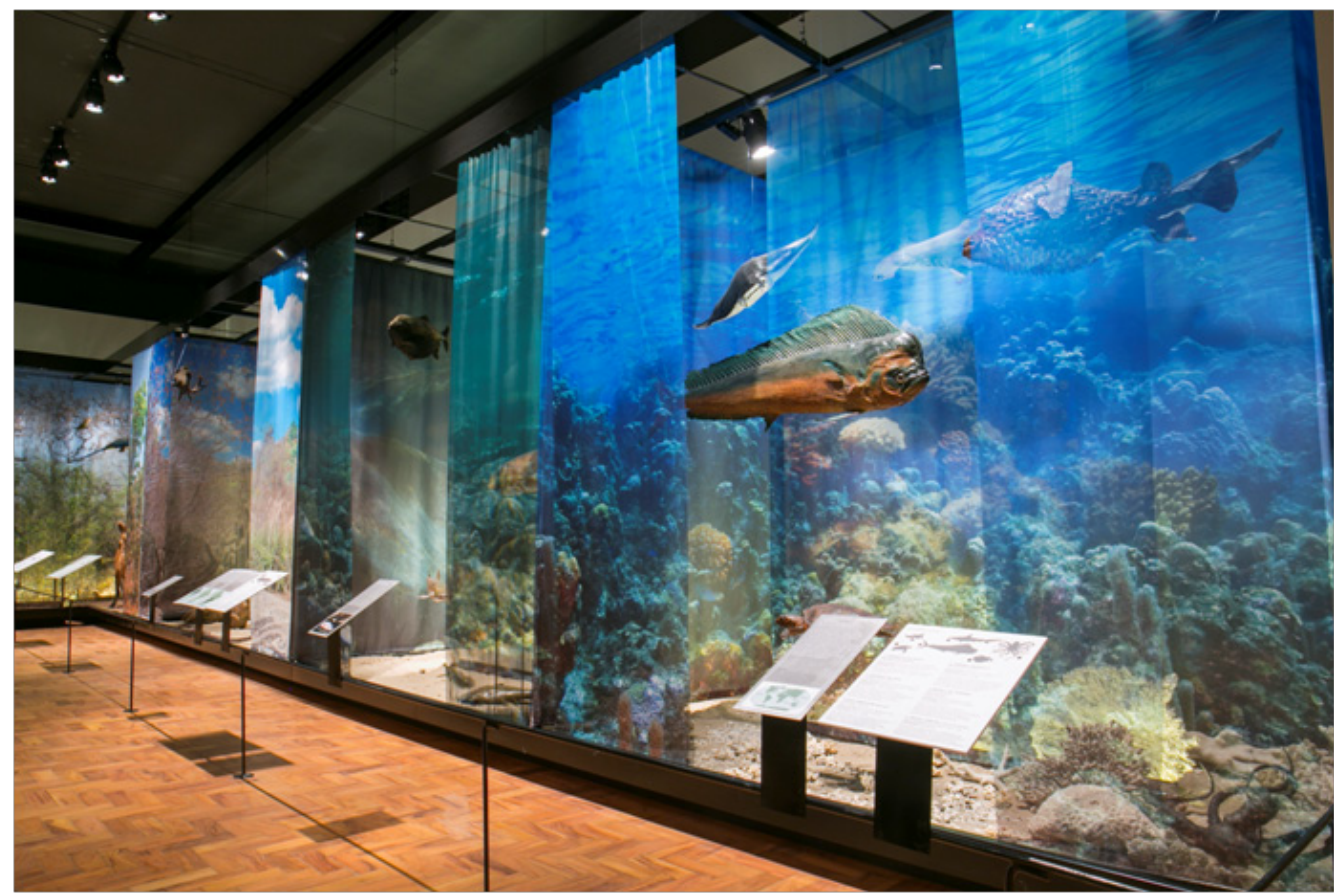

Figura I. Imagem do diorama que ilustra os ambientes marinhos ao lado da apresentação das paisagens brasileiras. Exposição de longa-duração "Biodiversidade: conhecer para preservar", MZUSP. Fotografia de Nanda Ferreira, 2015.

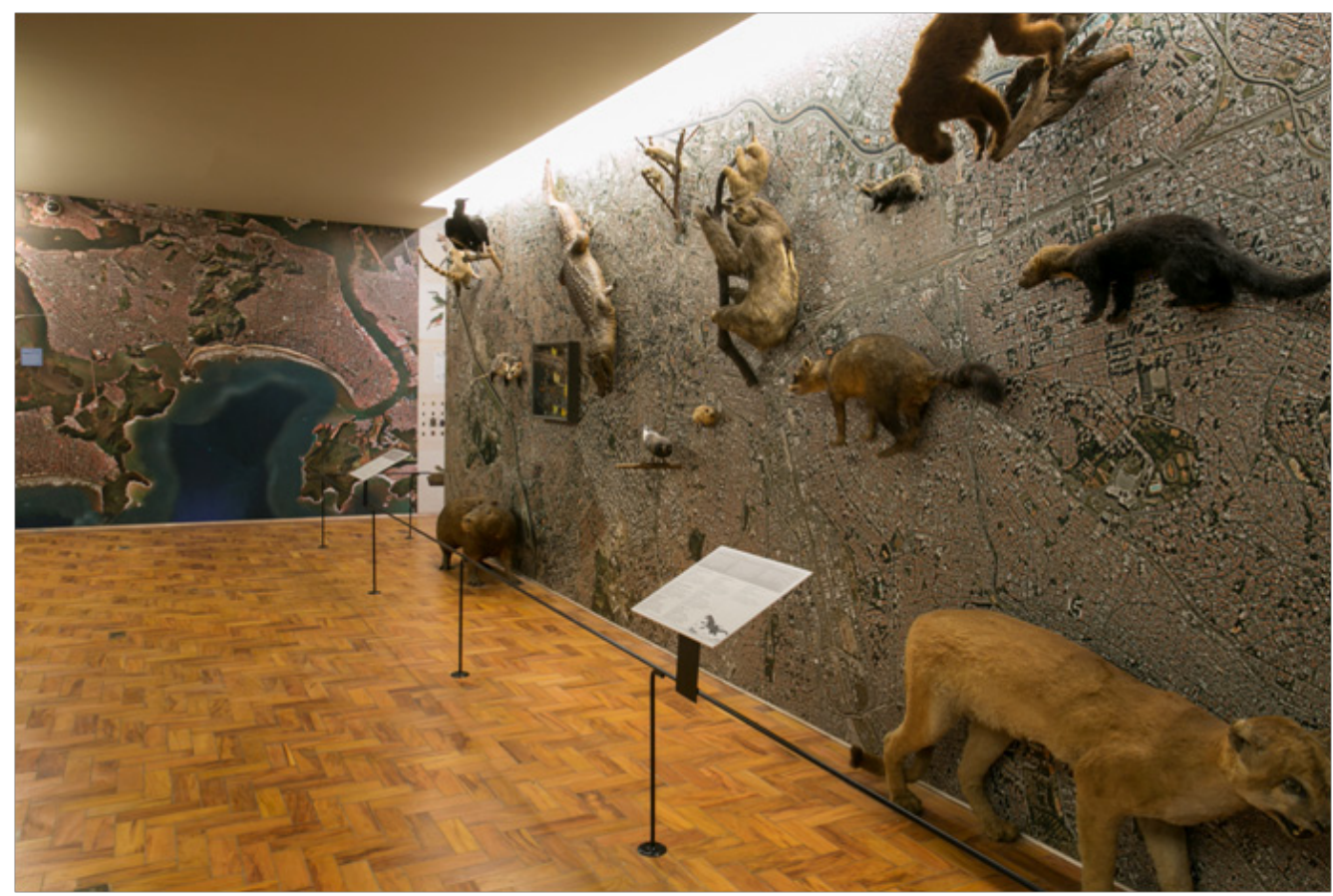

Figura 2. Imagem aérea da cidade de Santos (ao fundo) ilustrando o impacto dos ecossistemas urbanos sobre as zonas costeiras. Exposição "Biodiversidade: conhecer para preservar", MZUSP. Fotografia de Nanda Ferreira, 2015. 
de Serviços Ecossistêmicos que consideramos útil para salientar nossa dependência de recursos naturais.

Os curadores que trabalham com animais marinhos tiveram um papel decisivo durante as discussões sobre a apresentação destas paisagens. Insistiram na apresentação da cidade de Santos ilustrando o impacto que exercemos sobre as zonas costeiras. Desta forma, além da cidade de São Paulo, incluímos uma foto aérea da cidade de Santos (Fig. 2) abrindo espaço para que o tema fosse explorado em programas focais para o público.

Ao final da exposição encontramos nossa "Sala de Descobertas" que reproduz os bastidores do MZUSP com referências às coleções; ao rico acervo de nossa biblioteca; às bancadas de pesquisa na forma de uma grande mesa e equipamentos para as atividades com o público. Completa esta sala uma vitrine com os "novinhos em folha". Nela apresentamos os resultados recentes de nossa pesquisa. Lá aparece o trabalho da Malacologia sobre as ostras mencionado acima.

O tema dos oceanos ou animais marinhos também está presente em todas as nossas atividades paralelas. Hoje temos dois programa principais de atividades voltadas para o público: o "Tópicos em Zoologia”, onde promovemos palestras de divulgação científica no auditório do museu e o "Interatividade Animal”, onde usamos a nova Sala de Descobertas resultante da reconfiguração do espaço de nossa exposição. Desde o início destas atividades em 2016, ocorreram 10 palestras que abordaram a biodiversidade marinha e contamos ainda com cinco atividades interativas regulares em torno do tema. Não menos importante, estamos incluindo o dia 8 de junho, o Dia Mundial dos Oceanos da ONU, em nosso calendário de atividades nos juntando assim a este esforço coletivo e global para chamar a atenção do público para esta relevante causa.

\section{Considerações finais: nem tanto ao mar, nem tanto à terra}

A pesquisa no MZUSP está mais focada nas linhagens às quais os animais pertencem do que ao ambiente em que vivem.Ainda assim, as espécies marinhas e os estudos que suscitam figuram no acervo do museu e em suas linhas de pesquisa desde seus primórdios.

A pesquisa em ambiente marinho, por requerer maior aparato tecnológico (embarcações, equipamento de mergulho, etc) é mais difícil e custosa do que as coletas em terra firme. As parcerias institucionais foram e são relevantes contribuindo com o aumento das coleções dos diversos grupos como peixes, crustáceos, moluscos e outros invertebrados marinhos.

O conhecimento da fauna marinha do hemisfério sul parece estar em sua infância.A histórica atribuição de nomes de táxons do hemisfério norte para espécies que ocorrem aqui precisa ser reavaliada com base em exame de material depositado em diversas coleções. As diversas coleções do MZUSP desempenharão papel crucial neste processo. Ferramentas moleculares podem ser úteis se aliadas as tradicionais formas de reconhecimento e identificação de táxons.

Para a maior parte dos grupos, os desafios curatoriais são os mesmos tanto para os exemplares terrestres como para os marinhos, excluindo as já mencionadas estratégias de coleta. Entretanto, o desafio relativo a disponibilidade de espaço adequado à manutenção e crescimento das coleções foi mencionado por dois curadores. Por um lado, os mamíferos marinhos que apresentam baixa diversidade e grande escala de tamanho impõem desafios à sua armazenagem. Por outro lado, temos a inversão da escala que resulta no mesmo problema.A imensa diversidade dos pequenos invertebrados marinhos que uma vez corre- 
tamente triados e identificados exigirão uma área cerca de 50 vezes maior do que a que hoje ocupam para abrigar seus suportes.

O fortalecimento da pesquisa por meio da contratação de novo curador para a "nova" coleção de invertebrados marinhos terá impacto no crescimento das coleções e em nossos programas voltados ao público.

Precisamos contribuir na formação de especialistas para lidar com o vasto desconhecimento que existe sobre a biodiversidade marinha e promover o acesso ao estudo de nossas coleções. A mobilização internacional em torno do tema Oceanos, também terá impacto em nossa instituição. Nosso programa de comunicação também visa inspirar futuros pesquisadores. Buscamos sempre abordar conteúdos que sejam de interesse público. A partir de programas com temas específicos, podemos entrar em nossa questão prioritária que é a salvaguarda de nosso valioso acervo por meio da pesquisa e da conquista de novos cidadãos que valorizem a preservação da biodiversidade (Landim e Hingst-Zaher, 20l0) e que esta preocupação extrapole as tradicionais ciências da natureza. A partir da analogia de Latour (2015) uma vez de volta ao planeta natureza a humanidade precisa lembrar que um dos mais valorosos serviços prestado pela mesma é o de inspirar as nossas culturas e nossas relações simbólicas com nosso meio, rico de cores, formas, sons, cheiros e, aos nossos olhos, poesia.

\section{Referências}

ALHO, Cleber; REIS, Roberto; AQUINO, Pedro. Amazonian freshwater habitats experiencing environmental and socioeconomic threats affecting subsistence fisheries. Ambio, 44(5): 4I 2-425, 20 I 5.

AMARAL, Vanessa e SIMONE, Luiz. Revision of genus Cassostrea (Bivalvia: Ostreidae) of Brasil. Journal of Marine Biological Association of the United Kingdon. I-26. $20 \mid 4$.

BPBES - Plataforma Brasileira de Biodiversidade e Serviços Ecossistêmicos, 2017. https://www.bpbes.net.br/conheca-a-ipbes/ acessado em 24/03/2018.

CARVALHO, Marcelo; BOCKMANN, Flávio;AMORIM, Dalton; BRANDÃO Carlos; DEVIVO, Mário; FIGUEIREDO, Jose L; BRITSKI, Heraldo; DE PINNA Mário; MENEZES Naércio; MARQUES, Fernando; PAPAVERO, Nelson; CANCELLO, Eliana; CRISCI, Jorge; MCEACHRAN, John; SCHELLY, Robert; LUNDBERG, John; GILL, Anthony; BRITZ, Ralf;WHEELER, Quentin; STIASSNY, Melanie; PARENT, Lynne; PAGE, Larry;WHEELER,Ward; FAIVOVICH, Julián;VARI, Richard; GRANDE, HUMPHRIES, Lance; DESALLE, Rob; EBACH, Malte; NELSON Gareth. Taxonomic Impediment or Impediment to Taxonomy? A Commentary on Systematics and the Cybertaxonomic-Automation Paradigm. Evolutionary Biology. 34 (3-4): | 40- | $43,2007$.

CARVALHO, Paula. O Museu Sertório: uma coleção particular em São Paulo no final do século XIX (primeiro acervo do Museu Paulista). Anais do Museu Paulista, 23(2) I89-20I, 2014.

CARVALHO, Paula. De uma "cientificidade difusa": o coronel e as práticas colecionistas do Museu Sertório na São Paulo em fins do século XIX. Anais do Museu 
Paulista, 22(2) I05-I52, 2015.

COSTELLO, Mark; COLL, Marta; DANOVARO, Roberto; HALPIN, Pat; OJAVEER, Henn; MILOSLAVICH, Patricia.A Census of Marine Biodiversity Knowledge, Resources, and Future Challenges. PLoS ONE 5(8): el 21 I0, 2010.

COSTELO, Mark J. e CHAUDHARY, Chhaya. Marine Biodiversity, Biogeography, Deep-Sea Gradients, and Conservation. Current Biology, Elsevier, 27: 5 I I-527, 2017.

CRUTZEN, Paul. The geology of mankind. Nature, 425: p.23, 2002.

DORFMAN, Eric. The Future of Natural History Collections. New York, Routledge. 2018.

DORFMAN, Eric. LANDIM, Isabel, KAMEI, Osamu. 2018. The Future of Natural History Collections: general discussion. In: The Future of Natural History Collections. New York, Routledge. 2018.

DUARTE, Carlos. The Exploration of Marine Biodiversity: Scientific and Technological Challenges. Bilbao, Fundación BBVA. 2006.

FUNK,Vicki A.The erosion of collection-based science: alarming trend or coincidence? Washington, The Plant Press New series.V. I7 (4): I- I 3 e I4, 20 I4.

GROLA, Diego; CARVALHO, Paula; BARBUY, Heloisa. Nurturing Collecting and the Trade in Objects: The Formation of the Museu Paulista, 1850s-1910s. Museum History Journal, 9 (I): 93-107, 2016.

JAUME, Damiá e DUARTE, Carlos. General Aspects Concerning Marine and Terrestrial Biodiversity. In: The Exploration of Marine Biodiversity: Scientific and Technological Challenges. Bilbao, Fundación BBVA. 2006.

KEMP, Christopher. The Lost Species: Great Expeditions in the Collections of Natural History Museums. University of Chicago Press, 2017.

LANDIM, M. Isabel. e HINGST-ZAHER, Erika. Brazil's Biodiversity crisis: natural history collections are vital to preserve Brazil's biomes. ICOM News, 2010 (2): |4-|5.

LATOUR, Bruno. Telling Friends from Foes in the Time of the Anthropocene. In: The Anthropocene and the Global Environmental Crisis: rethinking modernity in a new epoch (Routledge Environmental Humanities). Devon, Taylor and Francis, 2015. 
SE, R; HAJBANE, S; CUNSOLO, S; SCHWARZ, A; LEVIVIER, A; NOBLE, K; DEBELJAK, P; MARAL, H; SCHOENEICH; ARGENT, R; BRAMBINI, R; REISSER, J. Evidence that the Great Pacific Garbage Patch is rapidly accumulating plastic.. Scientific Reports 8 (4666), 2018.

LOPES, M. Margaret. O Brasil Descobre a Pesquisa Científica: os museus e as ciências naturais no século XIX. Brasília, Ed. Hucitec. 1997.

MENEZES, Narécio; FIGUEIREDO, José L. e BRITSKI, Heraldo. Ichthyologycal Collection Building at the Museu de Zoologia da Universidade de São Paulo, Brazil. In: Collection Building in Ichthyology and Herpetology. Lawrence, American Society of Ichthyologist and Herpetologists, Special Publication n3, 1997.

NOGUEIRA C, BUCKUP PA, MENEZES NA, OYAKAWA OT, KASECKER TP, Restricted-Range Fishes and the Conservation of Brazilian Freshwaters. PLoS ONE 5(6): el I390, 2010.

ROBERTS, Callum. The Unatural History of the Sea. New York. Ed Shearwater Books, 2007.

SNELGROVE, Paul. Discoveries of the Census of Marine Life: Making Ocean Life Count . Cambridge University Press, 2010.

WEN, J.; ICKERT-BOND, S. M. Collection-based systematics: oportunities and outlook for 2050. Journal of Systematics and Evolution, 53 (6):477-488, 2015. 